\title{
UV-Induced Oxidative Stress in Cyanobacteria: How Life is able to Survive?
}

Rajesh P. Rastogi* and Datta Madamwar

BRD School of Biosciences, Sardar Patel Maidan, Vadtal Road, Satellite Campus, Sardar Patel University, Gujarat, India

*Corresponding author: Rajesh P. Rastogi, BRD School of Biosciences, Sardar Patel Maidan, Vadtal Road, Satellite Campus, Post Box No. 39, Sardar Patel University, Vallabh Vidyanagar 388 120, Anand, Gujarat, India, Tel: +91 02692 229380; Fax: +91 02692 237258; E-mail: raj_rastogi@rediffmail.com

Rec date: Feb 06, 2015; Acc Date: Apr 15, 2015; Pub date: Apr 17, 2015

Copyright: @ 2015 Rastogi PR, et al. This is an open-access article distributed under the terms of the Creative Commons Attribution License, which permits unrestricted use, distribution, and reproduction in any medium, provided the original author and source are credited.

\section{Short Communication}

Cyanobacteria are the most primitive and important prokaryotic component of photoautotrophic microflora on the planet Earth. They are ubiquitous in nature [1], maintaining the trophic energy dynamics of aquatic and terrestrial ecosystems [2,3]. Probably, they appeared on the Earth between 2.8-3.5 billion years ago during the Precambrian era [4] and led to the evolution of existing aerobic life on the Earth's atmosphere due to their inherent capacity of photosynthesis mediated oxygen evolution [5]. Adaptive diversification and inclusive survival of cyanobacteria in a range of ecological niches has ensued a large and diverse array of photosynthetic and other biomolecules, each with specialized functions to compete them successfully on the planet. These organisms have inherent capacity to fix atmospheric nitrogen and are source of several natural products of high economic values [6]. They play an important role in the nutrient (e.g. nitrogen, carbon, and oxygen) cycles and are being employed as a potential source of biofuels or green energy.

During the past few decades, increase in solar ultraviolet (UV) radiation due to anthropogenically released ozone depleting substances has aroused severe concerns about its deleterious effects on all sun-exposed organisms including cyanobacteria [7,8]. Being an obligate photo-autotroph and crucial demand of photo-energy to maintain the normal cellular physiology and biochemistry exposes cyanobacteria to a wide range of fluctuating environments of intense solar radiation with high UV (280-400 nm) fluxes in their natural habitats. Herein, the recent advances on survival of cyanobacteria against UV-induced oxidative stress have been briefly discussed.

UV radiation (particularly UV-B: 280-315 nm) may lead to oxidative stress in cyanobacteria by upsetting the cellular redox status. In photosynthetic organisms including cyanobacteria, ROS are generated by means of photosynthetic electron transport chain [9]. In contrast to algae and higher plants, cyanobacteria undergo a high degree of $\mathrm{O}_{2}$ reduction by consuming about $50 \%$ of the photosynthetic electrons instead of only $15 \%$ for plants [10]. It has been found that UV-B radiation has great efficacy to produce the reactive oxygen species (ROS) in cyanobacteria (Figure 1) [11].

Photo-induced oxidative stress may damage the cellular as well as biochemical integrity of a cell [12]. The high-energy short wavelength UV-B radiation may affect the biological systems either through direct effects on cellular DNA and proteins or indirectly by the generation of ROS [13,14]. It has been established that UV-A $(315-400 \mathrm{~nm})$ radiation which is not absorbed directly by the DNA molecules, can still damage it by producing a secondary DNA photoproducts via indirect photosensitizing reactions [15]. UV-B radiation brings about chemical modifications in DNA by the formation of purine/ pyrimidine dimers (Figure 2) and strand breaks leading to mutagenesis and loss of normal cellular metabolic functions $[16,17]$.
UV-induced oxidative stress may also induce DNA-DNA and DNAprotein cross links, base modifications and translocations [18]. It has been reported that DNA damage caused by UV radiation or ROS such as $\mathrm{OH}$ - radical results in ATM mediated phosphorylation of BID protein that induces cell-cycle arrest in S-phase [19,20]. Several oxidation products of purine bases such as 8-oxo-7,8-dihydroguanyl (8-oxoGua), 8-oxo-Ade, 6-diamino-4-hydroxy-5-formamidoguanine (FapyGua), FapyAde, and oxazolone have been reported to form upon exposure of DNA to UV-induced ROS [21-23]. UV-induced oxidative stress may damage proteins by site specific modifications of amino acid, aggregation of cross-linked reaction products, increased susceptibility to proteolysis and fragmentation of the peptide chain and oxidation of specific amino acids. ROS-mediated damage to photosynthetic apparatus followed by inhibition of photosynthesis has also been observed in cyanobacteria [16].
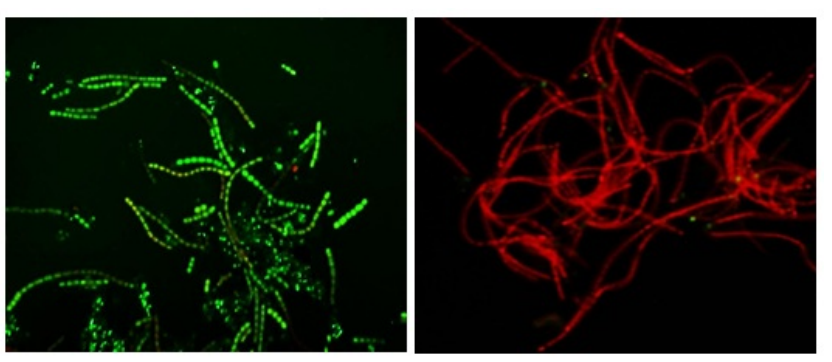

Figure 1: UV-induced generation of reactive oxygen species in the cyanobacterium Anabaena sp. A- UV-B exposed cells, B- UV-B control cells [11].

ROS are inevitably produced as intermediates of $\mathrm{O}_{2}$ reduction, or by its energization. It has been shown that intense solar light beyond the normal capacity of the photosynthetic electron flow may cause production of other ROS along with $1 \mathrm{O}_{2}$ leading to inactivation of photosystems. Moreover, ROS are mainly produced by PSI; however, light-driven oxidation of water occurs in PS-II and under certain conditions, PSII contributes to the overall production of ROS in the thylakoid membrane of plants, algae and cyanobacteria [24]. It has been stated that $1 \mathrm{O}_{2}$ produced by an energy input to oxygen $\left(\mathrm{O}_{2}\right)$ from photosensitized chlorophyll, is believed to inhibit the repair of photosystem II (PSII). The singlet oxygen $\left(\mathrm{O}_{2}\right)$, superoxide anion $\left(\mathrm{O}_{2}-\right)$, hydroxyl radical $\left(\mathrm{OH}^{-}\right)$and hydrogen peroxide $\left(\mathrm{H}_{2} \mathrm{O}_{2}\right)$ are potent free radicals. The ROS $1 \mathrm{O}_{2}$ and $\mathrm{OH}$ ' produced by energy input to oxygen, is believed to be highly reactive, and reacts with important cellular molecules such as DNA, proteins, pigments, lipids and enzymes leading to cell death. ROS reacts with fatty acids in the membrane lipid bilayer, cause lipid peroxidation leading to membrane leakage. Moreover, the general mechanisms of ROS-induced damage 
of biomolecules or dysfunction of cellular activities have been well documented [9,25-27]. Overall, UV-induced oxidative stress may affect the cellular morphology and vital processes such as cell growth and differentiation, motility and orientation, pigmentation and photosynthesis, $\mathrm{N}_{2} / \mathrm{CO}_{2}$ metabolism, enzyme activity as well as alteration in the native structure of proteins and DNA of cyanobacteria (Figure 3) [7,28-31].

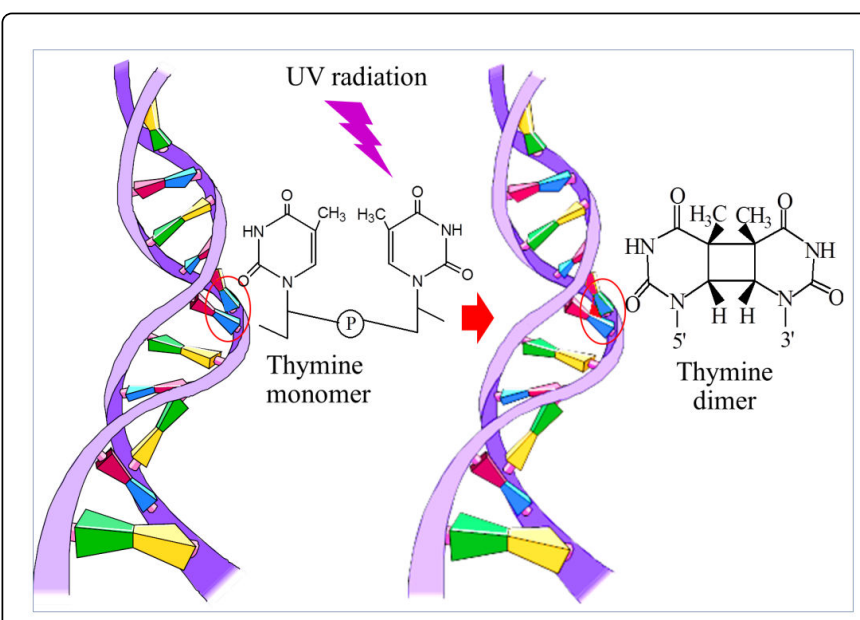

Figure 2: UV-B-induced formation of cyaclobutane thymine dimer on DNA strand.

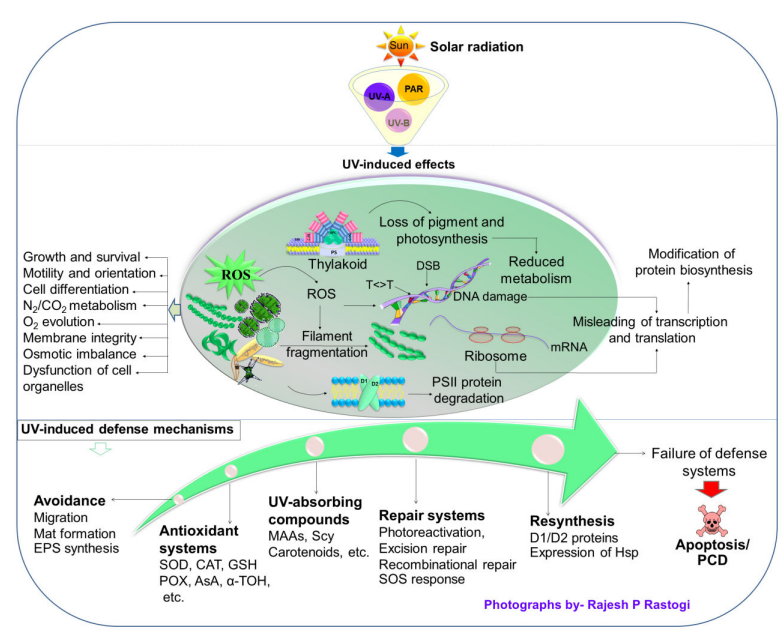

Figure 3: Effects of solar UV radiation on diverse photosynthetic life including cyanobacteria, and subsequent adoption of different defense mechanisms to counteract the harmful effects of short wavelength solar energy (modified from [7]).

Moreover, in-spite of several detrimental effects of UV-induced ROS and oxidative stress at cellular and biochemical levels as stated above, how cyanobacteria are still surviving and growing well in their natural habitats with high solar insolation? In fact, during the course of evolution cyanobacteria have developed several defence mechanisms such as avoidance (eg. migration and mat formation), DNA repair and heat dissipation mechanisms, synthesis of UVabsorbing/screening compounds and several antioxidant systems to counteract the damaging effects of UV-induced oxidative stress (Figure 3) [7,14,32].

A number of enzymatic (eg. ascorbate peroxidase, superoxide dismutase, catalase, glutathione peroxidase, glutathione reductase) and non-enzymatic (eg. carotenoids, ascorbic acid, $\alpha$-tocopherols and reduced glutathione) antioxidant defence mechanisms operated in cyanobacteria to minimize the UV-induced oxidative damage caused by ROS. The presence of antioxidant systems may exclusively regulate the homeostasis of ROS formation in cells. Some other group of secondary compounds such as polyamines with free radical scavenging activity have also been reported in cyanobacteria [33].

Cyanobacteria are capable of protecting themselves from harmful solar UV radiation by synthesizing some UV-absorbing/screening secondary biomolecules, such as the mycosporine-like amino acids (MAAs) and scytonemin (Scy) [34-38]. MAAs are intracellular, small, colorless and water-soluble molecules consisting of cyclohexenone or cyclohexenimine chromophores conjugated with the nitrogen substituent of an amino acids or its imino alcohol. Strong UV absorption maxima, high molar extinction coefficients, UV inducibility, stability against different abiotic factors such as temperature and UV radiation and potential antioxidant function strongly favour the UV-photoprotective role of MAAs in cyanobacteria. MAAs have capability to dissipate absorbed radiation efficiently as heat without producing ROS [39]. Some of the common MAAs found in cyanobacteria have been represented in (Figure 4). Scy ( $\lambda$ max: $386 \mathrm{~nm}$ ) is a yellow-brown lipid soluble pigment located in the extracellular polysaccharide sheath of some cyanobacteria (Figure 5) and protect them from UV radiation [40]. The synthesis of extracellular polysaccharides (EPS) also plays an important role in mitigation strategy against desiccation and harmful effects of UV radiation $[41,42]$.

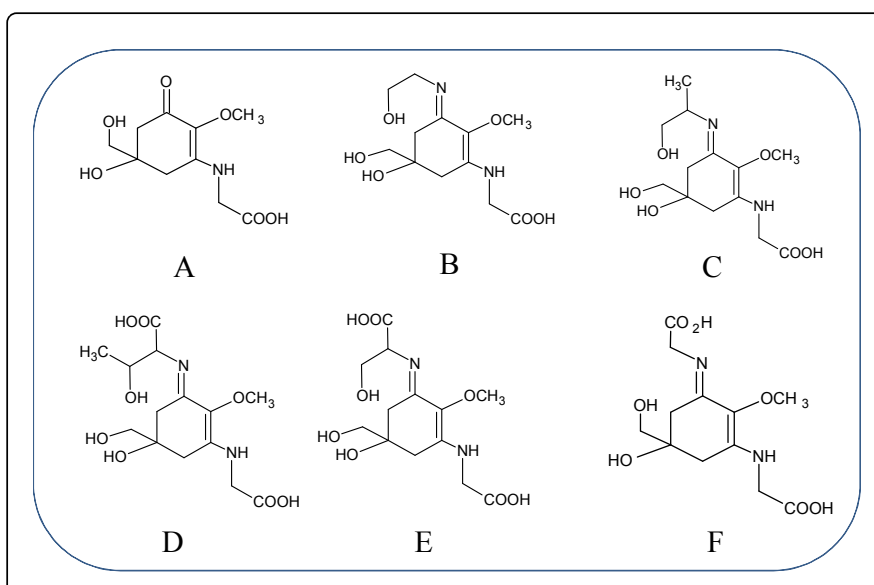

Figure 4: Chemical structure of some common MAAs reported in cyanobacteria. A-Mycosporine-glycine $(\lambda \max 310 \quad \mathrm{~nm}), \quad$ BAsterina-330 $(\lambda \max 330 \mathrm{~nm})$, C-Palythinol $(\lambda \max 332 \mathrm{~nm}), \mathrm{D}-$ Porphyra-334 $(\lambda \max 334 \mathrm{~nm})$, E- Shinorine $(\lambda \max 334 \mathrm{~nm})$ and FMycosporine-2-glycine $(\lambda \max 334 \mathrm{~nm})$.

Besides the role of UV-absorbing/screening compounds, the energy-dissipation mechanisms also play a vital role in photoprotection of cyanobacteria. It has been shown that under high light condition, the photoprotective heat/energy-dissipation mechanisms are activated that allow dissipation of excess energy in the form of heat by means of different pathway $[9,43]$. 


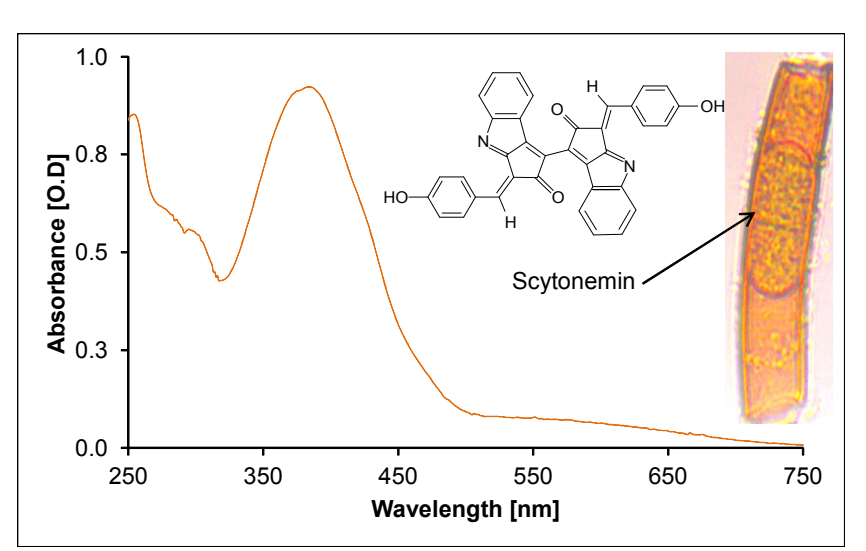

Figure 5: Extrcellular sheath pigment scytonemin and its UVabsorption maximum at $386 \mathrm{~nm}$ in the cyanobacterium Lyngbya sp.

It has been reported that most of the cyanobacteria can dissipate energy from phycobilisomes by means of photoactive soluble orange carotenoid protein (OCP) [43].

A number of repair mechanisms such as photoreactivation, excision repair such as base excision repair (BER) and nucleotide excision repair (NER) and recombinational repair have been reported in several organisms including cyanobacteria [14,44]. Photoreactivation (Figure 6) is the most efficient DNA repair mechanisms in cyanobacteria. The enzyme DNA photolyase play a vital role in photoreversal of the most cytotoxic and mutagenic DNA lesions such as cyclobutane thymine dimers $(\mathrm{T}<>\mathrm{T})$ or $6-4 \mathrm{PPs}$. The enzyme photolyase binds precisely to the CPDs (for CPD photolyase) or 6-4PPs (for 6-4 photolyase) and directly monomerizes the cyclobutane ring of the purine/pyrimidine DNA lesion using the energy of visible/blue-light and protects the genome from damaging effects of UV radiation $[45,46]$.

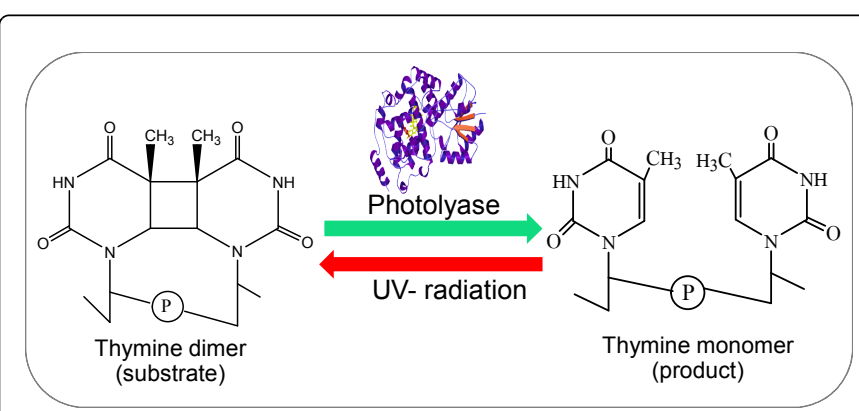

Figure 6: Photoreversal of thymine dimer in the presence of photolyase [14].

Overall, oxidative-stress-induced changes in general physiology and biochemistry may constitute ubiquitous threat to the accurate maintenance of the cellular and genomic integrity and survival of organisms; however, certain life forms such as cyanobacteria have motivated and devised a number of biochemical defence mechanisms to preserve their cellular machinery for competent endurance in adverse environment of UV-induced oxidative stress.

\section{Acknowledgement}

Rajesh P. Rastogi is thankful to the University Grant Commission (UGC), New Delhi, India for Dr. D.S. Kothari Postdoctoral Research Grant.

\section{References}

1. Whitton BA (2012) Ecology of cyanobacteria II. Their diversity in space and time. Springer, Dordrecht Heidelberg, New York, London.

2. Iturriaga R, Mitchell BG (1986) Chroococcoid cyanobacteria: a significant component in the food web dynamics of the open ocean. Mar Ecol Prog Ser 28: 291-297.

3. Stock CA, Dunne JP, John JG (2014) Global-scale carbon and energy flows through the marine planktonic food web: An analysis with a coupled physical-biological model. Prog Oceanogr 120: 1-28.

4. Fischer WW (2008) Biogeochemistry: Life before the rise of oxygen. Nature 455: 1051-1052.

5. Olson JM (2006) Photosynthesis in the Archean era. Photosynth Res 88: 109-117.

6. Rastogi RP, Sinha RP (2009) Biotechnological and industrial significance of cyanobacterial secondary metabolites. Biotechnol Adv 27: 521-539.

7. Rastogi RP, Sinha RP, Moh SH, Lee TK, Kottuparambil S et al. (2014) Ultraviolet radiation and cyanobacteria. J Photochem Photobiol B 141: 154-169.

8. Häder DP, Williamson CE, Wängberg SÅ, Rautio M, Rose KC, et al. (2015) Effects of UV radiation on aquatic ecosystems and interactions with other environmental factors. Photochem Photobiol Sci 14: 108-126.

9. Latifi A, Ruiz M, Zhang CC (2009) Oxidative stress in cyanobacteria. FEMS Microbiol Rev 33: 258-278.

10. Badger MR, von Caemmerer S, Ruuska S, Nakano H (2000) Electron flow to oxygen in higher plants and algae: rates and control of direct photoreduction (Mehler reaction) and rubsico oxygenase. Philos Trans $\mathrm{R}$ Soc Lond B; Biol Sci 355: 1433-1446.

11. Rastogi RP, Singh SP, Häder D-P, Sinha RP (2010) Detection of reactive oxygen species (ROS) by the oxidant sensing probe 2',7'dichlorodihydrofluorescein diacetate in the cyanobacterium Anabaena variabilis PCC 7937. Biochem Biophys Res Commun 397: 603-607.

12. Rastogi RP, Incharoensakdi A, Madamwar D (2014) Responses of a ricefield cyanobacterium Anabaena siamensis TISTR-8012 upon exposure to PAR and UV radiation. J Plant Physiol 171: 1545-1553.

13. Vincent WF, Neale PJ (2000) Mechanisms of UV damage to aquatic organisms. In: The Effects of UV Radiation on Marine Ecosystems, Cambridge Univ. Press, Cambridge. 149-176.

14. Rastogi RP, Richa, Kumar A, Tyagi MB, Sinha RP (2010) Molecular mechanisms of ultraviolet radiation-induced DNA damage and repair. J Nucleic Acids 2010: 592980.

15. Hargreaves A, Taiwo FA, Duggan O, Kirk SH, Ahmad SI (2007) Nearultraviolet photolysis of beta-phenylpyruvic acid generates free radicals and results in DNA damage. J Photochem Photobiol B 89: 110-116.

16. He YY, Häder D (2002) Reactive oxygen species and UV-B: effect on cyanobacteria. Photochem Photobiol Sci 1: 729-736.

17. Rastogi RP, Singh SP, Häder D-P, Sinha RP (2011) Ultraviolet-B-induced DNA damage and photorepair in the cyanobacterium Anabaena variabilis PCC 7937. Environ Exp Bot 74: 280-288.

18. Mercer J, Mahmoudi M, Bennett M (2007) DNA damage, p5 apoptosis and vascular disease. Mutat Res 621: 75-86.

19. Kamer I, Sarig R, Zaltsman Y, Niv H, Oberkovitz G, et al. (2005) Proapoptotic BID is an ATM effector in the DNA-damage response. Cell 122: 593-603.

20. Zinkel SS, Hurov KE, Ong C, Abtahi FM, Gross A, et al. (2005) A role for proapoptotic BID in the DNA-damage response. Cell 122: 579-591.

21. Doetsch PW, Zasatawny TH, Martin AM, Dizdaroglu M (1995) Monomeric base damage products from adenine, guanine, and thymine 
induced by exposure of DNA to ultraviolet radiation. Biochemistry 34 737-742.

22. Hall DB, Holmlin RE, Barton JK (1996) Oxidative DNA damage through long-range electron transfer. Nature 382: 731-735.

23. Cadet J, Sage E, Douki T (2005) Ultraviolet radiation-mediated damage to cellular DNA. Mutat Res 571: 3-17.

24. Pospísil P (2009) Production of reactive oxygen species by photosystem II. Biochim Biophys Acta 1787: 1151-1160.

25. Imlay JA (2003) Pathways of oxidative damage. Annu Rev Microbiol 57: 395-418.

26. Rinalducci S, Pedersen JZ, Zolla L (2008) Generation of reactive oxygen species upon strong visible light irradiation of isolated phycobilisomes from Synechocystis PCC 6803. Biochim Biophys Acta 1777: 417-424.

27. Blot N, Mella-Flores D, Six C, Corguillé GL, Boutte C, et al. (2011) Light history influences the response of the marine cyanobacterium Synechococcus sp. WH7803 to oxidative stress. Plant Physiol 156: 1934-1954.

28. Gao K, Yu H, Brown MT (2007) Solar PAR and UV radiation affects the physiology and morphology of the cyanobacterium Anabaena sp. PCC 7120. J Photochem Photobiol B 89: 117-124.

29. Sinha RP, Rastogi RP, Ambasht NK, Häder D-P (2008) Life of wetland cyanobacteria under enhancing solar UV-B radiation. Proc Natl Acad Sci, India, B 78: 53-65.

30. Rai S, Singh S, Shrivastava AK, Rai LC (2013) Salt and UV-B induced changes in Anabaena PCC 7120: physiological, proteomic and bioinformatic perspectives. Photosynth Res 118: 105-114.

31. Rastogi RP, Sonani RR, Madamwar D (2015) Effects of PAR and UV Radiation on the Structural and Functional Integrity of Phycocyanin Phycoerythrin and Allophycocyanin Isolated from the Marine Cyanobacterium Lyngbya sp. A09DM. Photochem Photobiol.

32. Banerjee M, Raghavan PS, Ballal A, Rajaram H, Apte SK (2013) Oxidative stress management in the filamentous, heterocystous, diazotrophic cyanobacterium, Anabaena PCC7120. Photosynth Res.

33. Incharoensakdi A, Jantaro S, Raksajit W, Maenpaa P (2010) Polyamines in cyanobacteria: biosynthesis, transport and abiotic stress response. In: Current Research, Technology and Education Topics in Applied Microbiology and Microbial Biotechnology (Ed. Mendez-Vilas A), Microbiology Book Series No. Vol. Formatex, Spain. 23-32.

34. Rastogi RP, Richa Sinha RP, Singh SP, Häder DP (2010) Photoprotective compounds from marine organisms. J Ind Microbiol Biotechnol 37: 537-558.
35. Rastogi RP, Sinha RP, Incharoensakdi A (2013) Partial characterization, UV-induction and photoprotective function of sunscreen pigment, scytonemin from Rivularia sp. HKAR-4. Chemosphere 93: 1874-1878.

36. Rastogi RP, Sonani RR, Madamwar D (2014) The high-energy radiation protectant extracellular sheath pigment scytonemin and its reduced counterpart in the cyanobacterium Scytonema sp. R77DM. Biores Technol 171: $396-400$.

37. Rastogi RP, Incharoensakdi A (2014) Characterization of UV-screening compounds, mycosporine-like amino acids, and scytonemin in the cyanobacterium Lyngbya sp. CU2555. FEMS Microbiol Ecol 87: 244-256.

38. Rastogi RP, Incharoensakdi A (2015) Occurrence and induction of a ultraviolet-absorbing substance in the cyanobacterium Fischerella muscicola TISTR8215. Phycol Res 63: 51-55.

39. Conde FR, Churio MS, Previtali CM (2000) The photoprotector mechanism of mycosporine-like amino acids. Excited-state properties and photostability of porphyra-334 in aqueous solution. J Photochem Photobiol B 56: 139-144.

40. Garcia-Pichel F, Sherry ND, Castenholz RW (1992) Evidence for an ultraviolet sunscreen role of the extracellular pigment scytonemin in the terrestrial cyanobacterium Chlorogloeopsis sp. Photochem Photobiol 56: 17-23.

41. Ehling-Schulz M, Bilger W, Scherer S (1997) UV-B-induced synthesis of photoprotective pigments and extracellular polysaccharides in the terrestrial cyanobacterium Nostoc commune. J Bacteriol 179: 1940-1945.

42. Chen LZ, Wang GH, Hong S, Liu A, Li C, et al. (2009) UV-B-induced oxidative damage and protective role of exopolysaccharides in desert cyanobacterium Microcoleus vaginatus. J Integr Plant Biol 51: 194-200.

43. Kirilovsky D, Kerfeld CA (2012) The orange carotenoid protein in photoprotection of photosystem II in cyanobacteria. Biochim Biophys Acta 1817: 158-166.

44. Essers J, Vermeulen W, Houtsmuller AB (2006) DNA damage repair: anytime, anywhere? Curr Opin Cell Biol 18: 240-246.

45. Kim ST, Heelis PF, Sancar A (1992) Energy transfer (deazaflavin-$>$ FADH2) and electron transfer (FADH2-->T $<>$ T) kinetics in Anacystis nidulans photolyase. Biochemistry 31: 11244-11248.

46. Essen LO, Klar T (2006) Light-driven DNA repair by photolyases. Cell Mol Life Sci 63: 1266-1277. 